\title{
A Metrópole Belém e sua centralidade na Amazônia Oriental Brasileira
}

\author{
Ana Cardoso. Universidade Federal do Pará, Belém, Brasil. \\ Danilo Fernandes. Universidade Federal do Pará, Belém, Brasil. \\ Ana Bastos. Universidade Federal do Pará, Belém, Brasil. \\ Cleidianne Sousa. Universidade Federal do Pará, Belém, Brasil.
}

RESUmo | Existe uma extensa discussão na literatura acerca das questôes de desmetropolização ou metropolização das cidades e seu papel nas suas áreas de influência. Nesta pesquisa se discute essa problemática na Região Metropolitana de Belém (RMB), capital do Estado do Pará, Amazônia brasileira. Recupera-se o processo histórico de formação do território dos quase 400 anos de Belém, e recorre-se a dados econômicos e estudos oficiais sobre a rede urbana brasileira, comparados às formulaçóes teóricas sobre o assunto, para demonstrar que coexistem duas dinâmicas na RMB, uma associada ao seu papel de cidade primaz da rede amazônica até meados do século xx, e outra à incorporação da região à dinâmica econômica brasileira após os anos 1950 . O trajeto seguido indica que, apesar da redução na participação da RMB no PIB do Estado do Pará, a expansão metropolitana e a especialização de serviços demonstram que esta assumiu novas funçôes e mantém as características de metrópole regional.

PALAVRAS-CHAVE | metropolização, rede urbana, cidades amazônicas.

ABSTRACT | In the literature, there is an extensive discussion on cities demetropolitanization or metropolization and their role across their area of influence. This study discusses these issues taking as a subject the Metropolitan Region of Belém (RMB), capital of Para State, Brazilian Amazon. It recovers the history of the territorial development of Belém over almost 400 years, and using economic data and official former studies on Brazilian urban network, this paper seeks to demonstrate the coexistence of two dynamics in RMB. One associated to its role as the prime city within the Amazon network until the midtwentieth century, and another that reveals the incorporation of the region to the industrial capitalist dynamics of Brazil after the 1950s. We may say that despite of the ratio decreased in the State'GDP, RMB's metropolitan expansion and services specialization shows that it has actually assumed new functions and maintains the characteristics of a regional metropolis.

KEYWORDS | metropolitazion, urban network, Amazonian cities.

Recibido el 9 de marzo de 2014, aprobado el 27 de octubre de 2014

E-mail: Ana Cardoso, aclaudiacardoso@gmail.com | Danilo Fernandes, danfernandes2@hotmail.com | Ana Bastos, pbastos@ufpa.br |

Cleidianne Sousa, cleidianne@ufpa.br 


\section{Introduçáo}

A região metropolitana de Belém, atualmente com cerca de 2,4 milhóes de habitantes (Instituto Brasileiro de Geografia e Estatística [IBGE], 2010), apresenta especificidades próprias de sua inserção como metrópole regional na Amazônia. Aspectos ligados à migração campo-cidade e ao papel histórico da cidade de Belém como nó central de uma rede dendrítica (Corrêa, 1987), transformaram a capital e seu entorno em um dos principais mercados estruturadores da dinâmica econômica da Amazônia Oriental Brasileira. Essa característica histórica foi fortalecida e reestruturada recentemente pelo processo de migração da população de baixa renda das regiôes contíguas (principalmente Marajó e Baixo Tocantins), áreas não incluídas no escopo dos grandes projetos de capital intensivo implantados no Pará a partir dos anos 1960.

Tal dinâmica migratória regional, somada à expansão da fronteira urbana na Amazônia nos últimos anos, contribuiu para a metropolização de Belém durante as décadas de 1970 e 1980. Nesta perspectiva, a literatura que aborda o processo de desenvolvimento territorial ocorrido na Amazônia na segunda metade do século xx (Becker, 1982; Corrêa, 1987; Machado, 1992,1989), ressalta a importância do processo de integraçáo rodoviária (impulsionada pela expansão da fronteira) das regiōes sul e sudeste do Pará ao restante do país (eixos da Belém-Brasília e PA 150).

Neste sentido, segundo Trindade Jr. (1998), a expansão da fronteira e a da Regiáo Metropolitana de Belém seriam verso e reverso da mesma moeda, na medida em que esta Região Metropolitana passou a assumir novas centralidades ligadas às atividades de comércio e serviços oriundas do processo de desenvolvimento de atividades produtivas em sua área de influência. Estas características ligadas à integração territorial da Amazônia ao Brasil e à formação histórica da cidade de Belém como cidade primaz de um vasto território integrado por via fluvial; constituem-se em especificidades que destacam um duplo movimento que caracteriza, nos dias de hoje, o seu papel na formação da rede de cidades na Amazônia Oriental Brasileira.

Neste sentido, um dos principais objetivos do presente artigo é trazer para o debate historiográfico, hoje em voga sobre a Amazônia, o argumento sobre a especificidade da RMB como espaço urbano; onde ao mesmo tempo se conjuga uma centralidade econômica moderna, baseada em atividades de comércio e serviços que se organizam a partir de sua integração com os centros dinâmicos regionais, nacionais e internacionais, e uma economia tradicional que se organiza ainda principalmente por meio do transporte fluvial e da dinâmica das pequenas e médias atividades produtivas da região, assim como da dinâmica e fluxo das populaçóes ribeirinhas localizadas no entorno de seu hinterland. Essa localizaçáo urbana peculiar foi de fundamental importância para o desenvolvimento de uma nova dinâmica que tem impulso no final do século xx e que hoje compóe uma rede de comércio e serviços metropolitanos em escala ampliada.

Com o intuito de desenvolver os argumentos principais do presente trabalho, inicia-se com uma reconstituição da trajetória histórica de formação da RMB; em seguida desenvolve-se uma leitura geral do processo de metropolização no Brasil no século xx, com ênfase especial na Amazônia Oriental Brasileira; discute-se a posição 
atual da RMB no contexto de formação da rede de cidades na Amazônia; por fim analisa-se o processo de metropolização e desmetropolização em curso vis-a-vis à evolução recente da Estrutura do Mercado de Trabalho e da Participação Setorial do PIB da RMB.

\section{Formaçáo histórica da Regiáo Metropolitana de Belém}

O aglomerado que originou a cidade de Belém surgiu como posto de defesa e entreposto comercial das rotas coloniais portuguesas a partir do século XVII. Esse núcleo assumiu os serviços de controle de produção e exportação da economia colonial devido à sua posição estratégica na desembocadura de grandes rios (Pará, Tocantins e Amazonas), à época único modal de transporte da região. Com o decorrer do tempo, o aglomerado urbano se expandiu, avançou sobre a floresta, se diversificou e se destacou dos demais. Por séculos, Belém prosseguiu como base para a exportação de produtos amazônicos.

A distribuição de assentamentos ao longo dos grandes rios, como local de armazenagem da produção extrativista, foi uma estratégia colonial importante para a penetração na floresta e exploração de seus recursos naturais. Essa formação estruturou uma rede dendritica, típica de sociedades de economia mercantil em que Belém desempenhava a função de cidade primaz, e que lhe garantiu a condição de principal porto de toda a Amazônia brasileira até o início do século xx (Corrêa, 1987; Vicentini, 2004).

Com a organização produtiva do extrativismo em grande escala, passaram a circular na cidade funcionários da administração colonial e comerciantes, prestadores de serviços e membros do clero que, aos poucos, consolidaram uma estrutura e um corpo locais. Dada a natureza contábil e administrativa das atividades mercantis, a paisagem da cidade e a gestão do comércio passaram a expressar o sucesso ou fracasso dos ciclos de produto (drogas do sertão, borracha, etc.) e viabilizam a formação de elites locais que modelaram a cidade a partir de suas visôes de civilizaçáo. O enriquecimento ocorrido durante o ciclo da borracha, que correspondeu à segunda metade do século xIX e primeira década do século xx, viabilizou transformaçóes importantes nessa organização sócio-espacial, com destaque para a implantação de uma ferrovia que estruturou a primeira ocupação contínua da Amazônia Oriental, ocorrida na regiāo Nordeste do Estado do Pará. Mesmo que os produtos da floresta chegassem por barco, a diversificação crescente das atividades econômicas aumentou a aglomeração de habitantes com outras preferências e criou a necessidade de abastecimento de outros produtos agrícolas, produzidos nessa regiáo.

A ferrovia ligava a capital, Belém, à cidade de Bragança, na costa atlântica, e se constituía em estratégia de ocupação do território completamente diferente da lógica ribeirinha dendrítica prevalecente até então (Vicentini, 2004). Era composta por três ramais: um se constituiu no eixo estruturador da ocupaçáo da segunda légua patrimonial de Belém ${ }^{1}$ (Ventura Neto, 2012); o segundo viu transformadas

1 Durante o período colonial, o território rural dos municípios brasileiros era de jurisdição da Coroa, que doava léguas patrimoniais para que fossem estabelecidas as freguesias que originavam as cidades. Após a Lei de Terras de 1850 , que estabeleceu a propriedade privada no país, as 
suas estaçóes na maioria das sedes municipais que compóem a RMB atualmente; e o terceiro originou o traçado do acesso por estrada de Belém ao resto do Brasil.

Após o fim do ciclo da borracha em 1910, a região nordeste do Pará continuou abastecendo a capital com produtos agrícolas, e na medida em que outras atividades foram associadas às paradas do trem, ocorreu a consolidação das novas aglomeraçóes (cidades e vilas) e adensamento da urbanização na regiáo, que passou a articular os núcleos de ocupação ribeirinha e continental. $\mathrm{O}$ crescimento da produção agrícola com base na agricultura camponesa se estabelecia inequivocamente e favorecia a formação de cidades e de relaçóes entre elas.

É relevante lembrar que, antes da integração nacional, Belém deteve centralidade mercantil e industrial no cenário regional, e contou com uma população migrante de diversas origens. Na primeira década do século $\mathrm{xx}$, a matriz europeia de vida cultural manifestou-se no respeitável número de jornais, revistas, agremiaçóes culturais e de salas de cinema existentes na cidade (Coelho, 2005). Em 1872 a cidade contava com $12 \%$ de estrangeiros na população, e destes $80 \%$ eram portugueses (Emmi, 2010), essa comunidade viabilizou equipamentos como o Hospital da Beneficiência implantado em 1877, que se mantém até hoje como referência no Estado. O cotidiano cosmopolita, a vida cultural intensa e as intervençôes urbanísticas de inspiração francesa promovidas por Antônio Lemos a partir de 1902 deram à cidade certa visibilidade internacional, ratificada pela existência de rotas diretas para a Europa, e pela prática de modismos da época (Sarges, 2002).

Em análise do setor industrial em Belém, Costa (2012b) discorre sobre o declínio relativo da cidade enquanto centro regional após a queda do preço da borracha. A opulência e a renda geral foram perdidas, o comércio e o extrativismo da borracha perderam participação no PIB, mas emergiram outras atividades com maior nível de diversificaçáo produtiva, abrangendo desde as atividades extrativas de outros produtos até a indústria, que no ano de 1907 estava constituída por 146 empresas e em 1940 por 912 unidades, concentrada predominantemente em Belém, onde o número de empregos era quase cinco vezes maior que nas outras duas cidades citadas na obra, Manaus e Rio Branco. Apesar da baixa incorporação tecnológica, esse fato manifestava uma diversidade de atividades inexistente em outras cidades amazônicas no mesmo período, mas incapaz de resistir aos efeitos do processo de integração implantados pelo governo federal a partir da abertura da BR 010 (Belém-Brasília). As tentativas de diversificação industrial não resistiram à concorrência criada pelas indústrias de outras regióes do país, ao que se pode acrescentar ainda as limitaçóes de condiçóes de financiamento, gerenciamento e a matriz energética da regiáo. Note-se que estas iniciativas de industrialização ocorreram em Belém por iniciativa do setor privado, meio século antes do início das açóes do governo federal para integração da Amazônia, em resposta ao isolamento da região em relação ao resto do país, e graças à reserva de capital mercantil acumulada no decorrer do ciclo da borracha.

Em Belém, a atividade industrial floresceu até o fim da Segunda Grande Guerra, concentrada no bairro do Reduto, adjacente à área portuária (ver Figura 1). No

cidades maiores receberam uma segunda légua patrimonial para garantir o domínio municipal que, contudo, respeitaram a ocupação privada já constituída. Ver Marx (1991). 
entanto, o fechamento das indústrias no final dos anos 1950 transformou o patrimônio imobiliário no ativo mais expressivo do espólio industrial, sobrevalorizado décadas depois com uma ação de macrodrenagem nessa área industrial da cidade ${ }^{2}$. Essa ação de macrodrenagem foi promovida pelo governo federal, e se estendeu desde os anos 1960 até os anos 1980 viabilizando a operação imobiliária mais bemsucedida da cidade (Ventura Neto, 2012).

\section{Figura I | Mapa mostrando extensão da Primeira Légua Patrimonial}

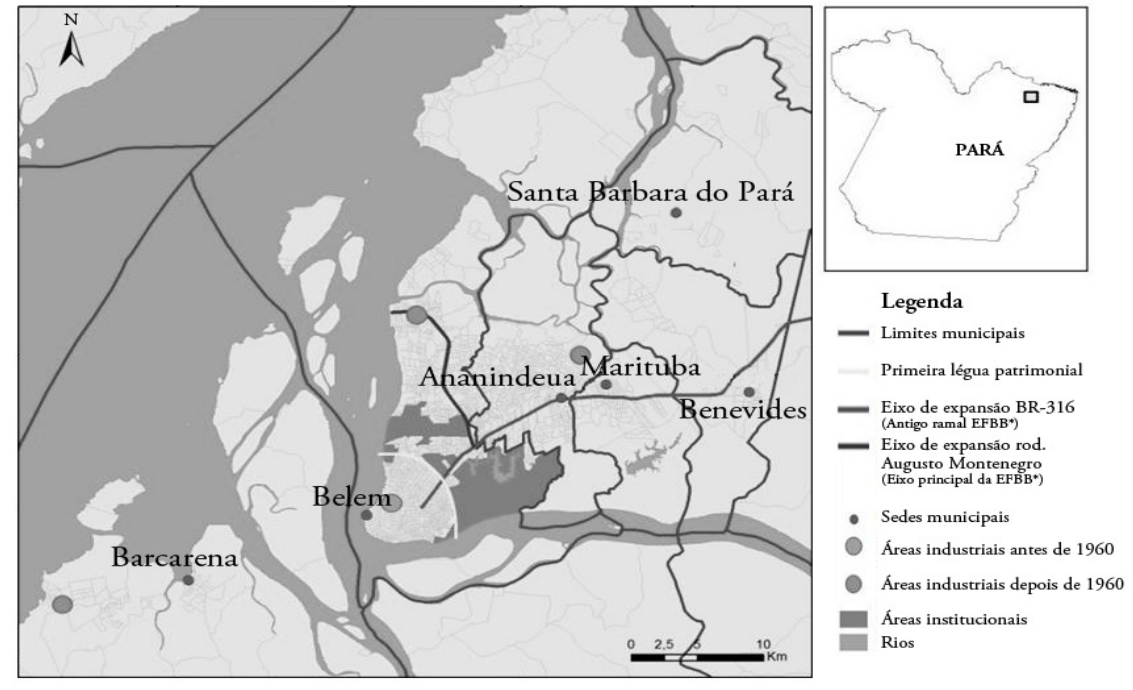

FONTE WWW.IBGE.GOV.BR. ELABORAÇÃo PRÓPRIA

Por outro lado, dentre as açóes do governo federal direcionadas para as demais regiōes do Estado, destacam-se a partir do final da década de 1970 o projeto Carajás, que abrangeu construção de infraestrutura de logística (instalação de porto em Barcarena, construção da Usina Hidroelétrica (UHE) em Tucuruí, rodovias, linhas de transmissão, etc.), extração mineral de ferro e bauxita, e implantação de complexo de produção de alumina em Barcarena, que se tornou a área industrial mais expressiva sob influência da RMB (ver Figura 1). Por outro lado, os distritos industriais introduzidos em Icoaraci (Belém), e em Ananindeua por iniciativa dos respectivos municípios e os parques de ciência e tecnologia nas cidades de Belém, Marabá e Santarém, iniciativas do Governo do Estado, nunca decolaram, revelando-se infrutíferos os esforços no estabelecimento de aglomerados produtivos, no espaço, que se revelaram tão promissores em outras regiôes do globo (Belussi, 1996).

Nesta perspectiva é possível identificar duas dinâmicas econômicas operando simultaneamente na capital do estado do Pará, uma decorrente da sua posição na rede dendritica, que ainda é funcional para as práticas tradicionais e estratégias territoriais da população ribeirinha e também para as elites da economia mercantil que 
atuam historicamente na região; e outra associada à industrialização nacional e à ação do grande capital na região, implantadas a partir das intervençôes federais, e que acompanham os processos metropolitanos típicos do país, apesar da condição periférica da Amazônia e da manifestação de padrôes de fronteira na economia e nos movimentos populacionais no Estado.

\section{O Processo Histórico de Metropolizaçáo e Desmetropolizaçáo no Brasil}

Em geral, na literatura que trata do problema da questão urbana e do debate sobre o processo histórico, e estrutural, de tendência à metropolização das cidades brasileiras, costuma-se chamar atenção para alguns aspectos que dizem respeito principalmente: ao processo de industrialização, aos problemas agrários, as diversidades regionais e à migração campo-cidade como elementos-chave capazes de explicar o processo caótico de metropolização no país. Milton Santos (1993) defende neste contexto que o processo de desconcentração, característico dos anos 1970 e 1980, estaria ocorrendo no Brasil de modo sincronizado ao próprio movimento de metropolização, uma vez que, ao processo de crescimento econômico e populacional das cidades médias, corresponderia uma tendência ao crescimento do nível de centralidade urbana nos grandes centros metropolitanos, indicando crescente centralização e metropolização em todo o país.

Segundo a formulaçáo de Milton Santos, apesar da reversão da tendência à concentração produtiva nos grandes centros urbanos no país, não estaria ocorrendo uma perda generalizada de centralidade das metrópoles brasileiras como um todo. Estar-se-ia se constituindo, em verdade, uma nova configuração do espaço (restruturação urbano-industrial), e um processo de desconcentração sócio-espacial e não de descentralização (Santos, 1993). Neste sentido, de acordo com Lencioni (1994), geralmente o que se dispersa são as unidades industriais, e não a concentração do capital e o comando de seus fluxos que, na verdade, continuam centralizando a decisão e o investimento no centro da metrópole; mantendo, portanto, a centralidade da mesma, constituindo-se em nova forma do espaço metropolitano, que a autora chama de metrópole desconcentrada (Lencioni, 1994; Trindade Jr., 1998).

Como resultado desse processo, as cidades médias crescem e assumem maior importância, sem, no entanto, diminuir funções das regiōes metropolitanas. Essas mantêm condiçóes de crescimento e suas centralidades perante a suas áreas de influência. Tal dinâmica favorece em última instância um potencial de convergência espacial metropolitana e promove a expansão metropolitana, ou ampliação de seus espaços urbano e periurbano, por meio de eixos privilegiados de acesso e alcance do capital industrial e financeiro em crescente valorização.

Partindo dessa caracterização do processo de metropolização (desmetropolização) no país, tal como apresentados por Santos (1993) entre outros, estudos mais recentes têm demonstrado uma tendência da rede urbana brasileira no sentido do fortalecimento dessa sua característica mais geral de combinar um processo de crescimento do número de cidades médias, ao mesmo tempo em que continua aumentando o papel de centralidade das regióes metropolitanas. Ou seja, que mesmo e apesar do processo de crescimento do número de pessoas vivendo nas cidades 
médias, as regióes metropolitanas continuam crescendo e exercendo um papel de fundamental importância como centros difusores e polos irradiadores de atividades de comércio e serviços em escala nacional e regional importantes.

É neste sentido que podemos verificar ainda, de acordo com a Figura 2, que a configuração atual da hierarquia da rede de cidades brasileiras (inclusive em sua relação com a região Amazônica), se mantém fortemente organizada a partir de apenas algumas regióes metropolitanas como São Paulo, Brasília e Rio de Janeiro. Neste sentido é nítido o papel de centralidade nacional que ainda se mantém em torno da cidade de São Paulo, como um grande nó da rede de hierarquia de cidades no Brasil.

Figura 2 | Mapa da Rede de Cidades Brasileira
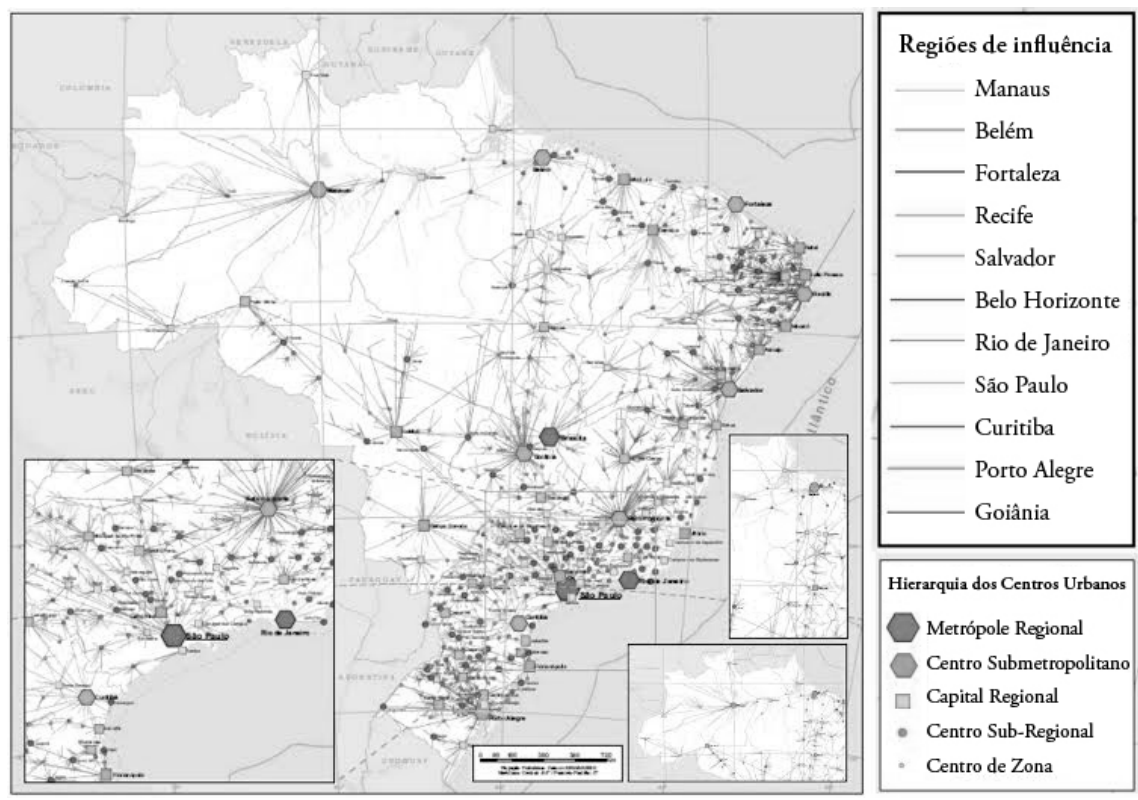

FONTE REGIC 2007 (IBGE, 2008: I 2)

Por outro lado, podemos verificar ainda, da mesma forma como em todo o Brasil, que na Amazônia Oriental ocorre um processo semelhante de manutenção do papel de centralidade da Rмв. Ou seja, que apesar da perda de parte de sua participação produtiva e da tendência à diversificação das atividades econômicas na região, a RMB continua mantendo o seu papel como nó central da rede de cidades em um vasto território. Isso tudo ao mesmo tempo em que se intensifica o processo de crescimento das cidades médias e a consolidação de algumas novas áreas metropolitanas como as Regiốes Metropolitanas de Manaus e São Luis.

Reforçando ainda este último movimento, novas cidades médias, como Santarém, Paragominas e Marabá, consolidam-se também como conexóes importantes no processo de integração da região amazônica com a dinâmica econômica nacional 
e internacional. $\mathrm{O}$ que levaria alguns pesquisadores a afirmar de maneira apressada que estaria ocorrendo de modo definitivo um processo de perda de influência e centralidade da RMB em relação a seu papel inclusive na formação da rede de cidades da Amazônia Oriental. Tal Processo deve ser visto com cautela, tendo em vista sua perspectiva histórica e a necessidade de se levar em consideração outras dinâmicas territoriais em curso na região.

\section{A posição de Belém na rede urbana da Amazônia Oriental Brasileira}

Ao longo da segunda metade do século xx, o processo de integração da Amazônia ao restante do território nacional, ocorre pelo consumo dos bens produzidos na regiáo sudeste, onde se concentraram todos os esforços de industrialização do país. No modelo de industrialização brasileira as regióes periféricas participaram na formação de mercado consumidor nacional. Esse fato, aliado à expansáo da fronteira agropecuária na Amazônia Oriental, alteraram completamente o papel histórico que Belém desempenhava como nó principal de integração entre o mercado regional, formado pela rede de comércio e serviço existente nas pequenas cidades no interior da Amazônia, e a dinâmica econômica internacional. Os novos eixos de integração nacional permitiram maior articulaçáo e crescimento de cidades médias no interior do Pará, tendência intensificada na medida em que o transporte rodoviário substituiu em parte o transporte fluvial. Isso promoveu a integração da regiáo aos mercados nacionais de produtos e serviços e a formação de uma "base logística" para o processo de ocupação da fronteira (Becker, 1982, 1987; Machado, 1992; Mitschein Miranda \& Paraense, 1989).

O princípio norteador dos anos 1970, de que a Amazônia seria uma "terra sem homens para homens sem terra" gerou um massivo fluxo migratório para a região norte, o qual foi direcionado originalmente para os assentamentos rurais, grandes obras de infraestrutura logística e projetos de exploraçáo mineral, açóes com financiamento externo que, após as mudanças nas taxas de juros motivadas pela crise internacional do petróleo, inviabilizaram a continuidade desses investimentos (Araújo, 1999). Paralelamente aos grandes investimentos federais, o Ministério do Interior e o Serviço Brasileiro de Habitação e Urbanismo (SERFHAu) assumiram as açóes de diagnóstico, planejamento e capacitação técnica relativa ao processo de urbanização e de expansão das cidades na Amazônia (Ministério do Interior/ SERfHAU, 1972), e o Instituto de Colonização e Reforma Agrária (INCRA) formulou uma proposta de Urbanismo Rural para apoio dos assentamentos rurais implantados na área de influência da rodovia Transamazônica (Camargo, 1973). Essas açôes tiveram pouca efetividade sobre a condução do processo de urbanização na região e foram abortadas até a metade da década de 1970, quando todo o aparato de planejamento foi substituído pela operação do sistema habitacional através do Banco Nacional de Habitação. No âmbito regional houve redução da agenda do governo federal em andamento no Pará na década seguinte às áreas estratégicas, para o equilíbrio da balança comercial como a mineraçáo, ou para ampliar o potencial energético do país, com a implantação da uHE Tucuruí. 
Tal como em outras crises econômicas, a população migrante liberada das atividades rurais e das grandes obras passou a circular no território e gradativamente elegeu a capital como local de destino, iniciando um processo de redirecionamento do fluxo migratório, originalmente destinado a outras regiốes do Estado do Pará, para a região metropolitana. A função da Amazônia Oriental de receptáculo de mão de obra foi estimulada, entre outros aspectos, pelo processo de expansáo da fronteira agropecuária nacional, caracterizado por alto grau de concentração fundiária e pela modernização conservadora no campo (Costa, 2012a). A industrialização do país, sem uma clara proposta para o setor agrícola da região, resultou na deterioraçáo das condiçóes de vida do homem do campo no período, trazendo consigo a inviabilização de tradicionais modos de (re)produção da população cabocla do interior (Mitschein et al.,.. 1989). Em apenas duas décadas, a dinâmica migratória alcançou plenamente as cidades que já desempenhavam ou que assumiam papel de polo regional, introduzindo novos níveis hierárquicos na rede urbana em formação (IBGE, 2008).

Belém tornou-se o epicentro de uma nova centralidade, como evidência desse fenômeno observa-se que na base de dados dos Estudos de Regionalização de Cidades $^{3}$ - RegiC (IBGE, 2008) os municípios de Ananindeua, Marituba, Benevides e Barcarena aparecem incorporados na Área de Concentração Populacional de Belém, amalgamados na categoria Metrópole. Os municípios localizados no entorno da RMB que apresentaram alguma alteração de centralidade entre as pesquisas REGIC de 1966 a 2007 foram: Barcarena, que evoluiu de Centro Local B em 1966, para Centro Subregional B em 2007; São Miguel do Guamá, que passou da condição de Centro Local B para Centro Local em 2007, enquanto Castanhal manteve a mesma posição no período, Centro Sub-regional A.

Todos os demais municípios do entorno da RMB não sofreram alteração na sua condição de centro local, o mais baixo nível hierárquico da rede, confirmando a tendência à estagnação da maior parte dos municípios do entorno da RMB que estiveram excluídos do escopo dos "grandes projetos". A única exceção foi Barcarena, município que abrigou o porto internacional de carga a partir de1985 e indústrias ligadas à produção de alumina e caulim.

No decorrer deste mesmo período, no interior do Pará, as cidades de Santarém (fundada em 1661) e Marabá (1913), evoluíram de centros regionais para capitais regionais. Essas cidades eram originariamente cidades ribeirinhas que serviram de base de apoio para ciclos econômicos de abrangência mais restrita e também se articularam ao modal rodoviário. Cidades menores associadas a intervençóes federais, tais como: a) Itaituba (1812), de origem ribeirinha, mas incorporada ao trajeto da Rodovia Transamazônica; b) Paragominas (1965), criada a partir da implantação da Rodovia Belém-Brasília, e fortemente associada à exploração de madeira; c) Tucuruí (1782), cidade ribeirinha que recebeu a maior Usina Hidrelétrica Nacional (unE Tucuruí) e; d) Redenção (1972), localizada na área de intercessão da PA 287 com a BR 158 e BR 155 (antiga PA 150), ascenderam no período do último nível (centro local) para centros sub-regionais. Destaca-se o caso de Parauapebas (1983) que foi criada em

3 O último REgic (IBGe, 2008) adotou as seguintes classes para hierarquizar as cidades no Brasil: Metrópole, Capital Regional (A, B e C), Centro Sub-regional (A e B), Centro de Zona (A e B) e Centro Local. 
função da exploração de ferro na província de Carajás e tornou-se centro de zona no decorrer de apenas 24 anos. Observa-se que as cidades criadas após os anos 1960 estão diretamente associadas à abertura das rodovias, e nas cidades ribeirinhas que mais ascenderam ocorreu a articulação entre os modais rodoviário e hidroviário (ver Figura 3).

FIGURA 3 | Mapa mostrando a Regiáo Norte com a classificação de centralidades, com destaque para os municípios que sofreram significativa ascensão nos últimos 20 anos segundo classificaçôes do REGIC 2007

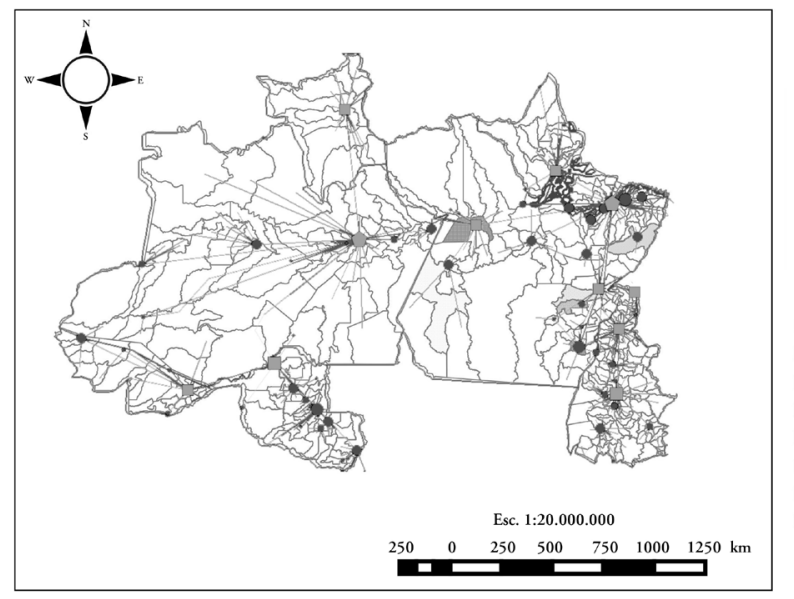

\section{Legenda}

Ligaçóes entre centros HERARQUIA DOS CENTROS URBANOS Metrópole Capital Regional A Capital Regional C

Centro Sub-regional A

Centro Sub-regional B

Centro local A

Centro local B

MUNICÍPIOS EM DESTAQUE

Barcarena

Itaituba

Marabá

Paragominas

- Parauapebas

- Redençáo

- Santarém

- Tucuruí

FONTE IBGE (2008)

Contudo, estudos macroeconômicos (Domingues, Carvalho \& Magalhães, 2013; Simóes, Garcia, Lima \& Amaral, 2013) revelam que apesar: a) dos grandes investimentos públicos e privados (mineração e agropecuária) historicamente realizados em áreas rurais ou próximo a cidades pequenas; b) do crescimento demográfico observado no Estado, e c) da redistribuição de população por diversas cidades do interior, permanece a tendência de fortalecimento da RMB em função do processo de consolidação dos municípios que estão conurbados com a capital. Simulaçóes desenvolvidas por Simóes et al. (2013) para o Pará que adotaram a metodologia do REGIC (IBGE, 2008) ${ }^{4}$, revelam que a rede urbana do Estado do Pará possui estruturas com limitadas possibilidades de alteração entre 2010 e 2020. Mesmo com atualizaçóes e readequação das variáveis para a realidade amazônica, observa-se clara manutenção

O estudo de Simóes et al (2013) realizou dois movimentos metodológicos: o primeiro atualizou o último REgiC com dados do Censo de 2010 (a base do estudo original foram os dados de 2000), o segundo recortou a Amazônia Legal e o Estado do Pará e assumiu os subníveis hierárquicos originais como classes de cidades, e maior ponderação para variáveis de maior relevância para a regiáo Amazônica (maior peso para crescimento demográfico e PIB). A partir dessa base realizou simulaçóes para 2010 e 2020. Na atualização do REGIC, Ananindeua emergiu como capital regional, enquanto nas projeçôes, Marituba e Castanhal apareceram como centros sub-regionais. A aglomeração resultante corresponde à RMB atual, consolida a importância de Belém e indica a tendência de manutenção de sua condição de metrópole na Regiấo Norte junto com Manaus. 
da polarização regional em áreas tradicionalmente mais dinâmicas (Bélem, Marabá e Santarém). As alteraçôes mais significativas ocorrem nos níveis hierárquicos mais baixos da rede urbana em formação, onde são introduzidas novas atividades via de regra associadas ao circuito superior da economia urbana (R. Santos, 1980), tais como, a mineração e a agropecuária voltadas para exportação, que por si só não garantem a ampliação de funçóes requerida para a consolidação da ascensão dessas pequenas cidades na rede urbana em formação. Por outro lado, o fortalecimento de municípios constituintes da RMB, seja pelo adensamento populacional, seja pelo acúmulo histórico de infraestrutura urbana consolidam a RMB como centro relacional, que sustenta sua centralidade em relação ao interior do Pará, (Trindade Jr. \& Pereira, 2007; Pinheiro, Pena, Amaral \& Herreros, 2011). Esta trajetória confirmaria a tese da metropolizaçáo espacialmente desconcentrada apresentada a seguir.

\section{Dinâmica econômica e espacial contemporânea da Regiáo Metropolitana de Belém: desmetropolizaçáo ou metropolização desconcentrada?}

O desenvolvimento da fronteira urbana na Amazônia após a década de 1960 foi fortemente articulado à intervenção estatal sobre o espaço regional amazônico (Becker, 1982). Vários autores ressaltam que a atuação do governo federal teria sido a principal responsável pela elaboração/implantação de um conjunto de políticas voltadas para o controle da terra, a migração induzida e o incentivo a grandes empreendimentos na Amazônia afetando significativamente o processo de expansão territorial na região (Becker, 1990; Machado, 1992; Pereira, 2006). Do debate original sobre a fronteira agropecuária espontânea na década de 70 (Martins, 1975; Sawyer, 1979), evolui-se de maneira consistente, a partir dos anos 80 , para uma interpretação alternativa em que os rumos e a importância da fronteira amazônica para a acumulação capitalista brasileira devem ser compreendidos como algo estruturado a partir de sua dinâmica urbana e industrial: alimentada direta ou indiretamente pelo Estado desenvolvimentista brasileiro das décadas de 1960, 1970 e 1980 (Monte-Mor, 2004; Becker, 2013). Ainda seguindo esta interpretação, considera-se que a partir da década de 1960 houve uma aceleração da aglomeração urbana nas cidades capitais potencializando o processo de metropolização através da abertura de novos espaços de circulação e de novos núcleos populacionais, não ribeirinhos, que contribuíram para a reestruturação da rede urbana dendrítica até então existente. Na Amazônia Oriental, toda a dinâmica de ocupação da fronteira repercutiu na urbanização de Belém e de sua Região Metropolitana que desde então tornou-se dependente de atividades terciárias, segundo trajetória diversa de Manaus, metrópole da Amazônia Ocidental, que teve seu crescimento pautado a partir do fortalecimento do setor industrial desde a criação da Zona Franca de Manaus em 1967 (Trindade Jr., 1998).

As iniciativas do governo militar de planejamento comprometido com a descentralização industrial se manifestam nas formulaçóes de vários planos de desenvolvimento voltados para a regiáo, dos quais se destacam o II Plano Nacional de Desenvolvimento (PND) e o Programa de Pólos Agropecuários e Agrominerais da Amazônia (Polamazônia) que impuseram um processo de reestruturação produtiva fortemente articulado à política de incentivos governamentais destinados aos grandes 
empreendimentos implantados na região, que se desdobrou no fortalecimento de cidades médias durante as décadas de 1970 e 1980. Na Amazônia Oriental, essa reestruturação produtiva aconteceu por meio dos incentivos fiscais praticados pela Superintendência de Desenvolvimento da Amazônia (Sudam) aos grandes projetos de mineração, provisão de infraestrutura logística e assentamentos agrícolas, e do financiamento do setor privado através dos recursos do Fundo Constitucional do Norte (FNO) fortemente orientado para empreendimentos agropecuários e madeireiros (Costa, 2012b).

Essa reestruturação produtiva instituiu uma nova dinâmica econômica, caracterizada pela migração do empresariado e dos investimentos para as localidades que apresentassem maiores vantagens comparativas em detrimento das possibilidades oferecidas pela capital (Belém). Os incentivos fiscais e a abertura de estradas viabilizaram um processo de desconcentração produtiva que contribuiu para o fortalecimento das cidades médias, e para a mudança das funçóes de centralidade da RMB em relação a determinadas regióes do interior do Estado do Pará, e à Amazônia brasileira. O já citado crescimento de cidades (assumidas nesse contexto regional como cidades médias) como Marabá e Santarém, enquadra-se nesse fenômeno, uma vez que tais cidades passaram a cumprir papel de Capitais Regionais $\mathrm{C}$ com a expansão da fronteira econômica ao longo das rodovias BR 010 e 230 respectivamente, enquanto Castanhal tornou-se Centro Subregional A, na BR 316 (Ribeiro, 2001; Pereira, 2006). Os portos de Marabá e Santarém já destacavam essas duas cidades ribeirinhas, que foram fortalecidas pelos novos modais rodoviário e aéreo, enquanto Castanhal constituiu-se em nó de estradas federais e estaduais que conectam a capital, a costa atlântica, a área de influência do Rio Guamá, o sudeste do Pará e os estados vizinhos de Maranhão e Tocantins.

Para Trindade Jr. (1998), este movimento de dispersão produtiva e populacional tem levado alguns autores a interpretarem esse processo erroneamente como fenômeno sinônimo de "desmetropolização", possivelmente fortalecido pelo debate regional sobre o papel das cidades médias vis-à-vis ao papel da Região Metropolitana de Belém, e sobre a situação da RMB diante da nova complexidade e da expansão da fronteira urbana na Amazônia Oriental Brasileira.

De acordo com pesquisa realizada pelo Instituto de Pesquisa Econômica Aplicada (Instituto de Pesquisa Econômica Aplicada [IPEA], 2001), e depois confirmado por relatório do CGEE (Brasil, 2008), a cidade de Belém estaria apresentando, apesar de seu papel estratégico como centro de fornecimento de serviços e comércio para uma grande área no seu entorno, tendência de perda de centralidade no Estado do Pará e na região Norte do país (IPEA/IbGe/Unicamp, 2001). Este fenômeno estaria acontecendo, segundo o estudo, na medida em que novos núcleos urbanos em franca expansão -como Palmas e Marabá, por um lado, e Itaituba e Santarém por outroque passaram a exercer funçóes concorrentes de centralidade, como centros urbanos emergentes e elos nucleadores e formadores de novos subsistemas de cidades cada vez mais importantes para a constituição de uma rede de cidades complexa e hierarquizada, em que cidades "médias", oferecem serviços para pequenas cidades, localidades em área rural, sempre com localização mais próximas às atividades produtivas mais importantes na região. Ao mesmo tempo em que estas cidades passam também 
a exercer, de modo complementar e concorrente, o papel de nós ou elos de integração intermediário da regiāo Norte em relação ao restante do país, diminuindo a importância relativa de Belém na rede de cidades e como elo de integração de toda a região em relação ao Brasil.

De acordo com essa interpretação, de um antigo centro hegemônico na Amazônia, organizador de uma rede de tipo dendritica (Corrêa, 1987), Belém estaria gradativamente assumindo menor centralidade regional (Ribeiro, 2001), apesar de manter uma importância ainda significativa como centro comercial e prestador de serviços em escala regional, ainda que tais funçôes mantenham condição de metrópole, mas em escala e relevância regional menores do que no passado.

De uma cidade que centralizava todas as ações de articulação do mundo exterior com a rede de cidades do interior da Amazônia, Belém ter-se-ia transformado em apenas mais um polo regional estratégico, ou "Centro Regional" (Ribeiro, 2001) entre outros, exportador de commodities, fornecedor de serviços e receptor de grandes contingentes populacionais que seriam relativamente mal absorvidos pela estrutura de empregos urbanos da "cidade", uma vez que náo dispóe de atividade industrial mais expressiva, e por isso não conseguiria dar resposta adequada aos desafios de uma sociedade crescentemente industrialista e com vocaçáo para a sociedade de consumo e com habitus de vida considerados como tipicamente urbanos.

No entanto, esta interpretaçáo pode ser contestada com o argumento de que apesar do aumento da complexidade da rede urbana na Amazônia Oriental brasileira a partir da década de 1960, Belém continuaria exercendo um papel de extrema importância, principalmente por servir como elo de interligação entre as atividades econômicas e os fluxos de comércio e serviços que alimentam a vida urbana na área de influência da região metropolitana. Além disso, a RMB passou a cumprir novas funçóes, ao tornar-se espaço de valorização de capital e eixo central por onde são canalizados os recursos e os excedentes gerados em empreendimentos industriais e agropecuários de vários pontos da rede urbana no interior do Estado do Pará, e de outros estados sob sua área de influência (como é o caso do Estado do Amapá).

Se por um lado a maior complexidade da rede de cidades na regiáo sudeste do Pará pode significar uma perda de centralidade da RMB na regiáo, por outro lado viabiliza o reposicionamento estratégico da RMB no processo de acumulação de capital, decorrente da integração da Amazônia Oriental às dinâmicas de desenvolvimento próprias do capitalismo monopolista e industrial brasileiro.

Quando se avalia o caso específico da Amazônia Oriental brasileira, percebe-se que a expansão da fronteira econômica e urbana, por meio da implantação dos grandes projetos mineradores, agropecuário e madeireiro nas regiôes sul e sudeste do Pará nas décadas de 1970 e 1980, geram para Belém o bônus do fortalecimento do centro urbano (metropolitano) que abriga a prestação de serviços (públicos e privados) de alguma forma impulsionados por aqueles empreendimentos, assim como o ônus da intensa migração populacional para a região no mesmo período (Ribeiro, 2001; Becker, 1990; Pereira, 2006).

Nesta perspectiva, a ideia de desmetropolização poderia ser descartada, ao se reconhecer a nova inserção do espaço metropolitano de Belém na dinâmica territorial em curso na região. O que geralmente se observa é um reforço da urbanização 
desconcentrada 5 , culminado assim num processo de metropolização ainda mais intenso, reforçado pelo fato de que o desenvolvimento expansivo da metrópole é determinado mais pela abrangência de processos territoriais do que propriamente por limites administrativos.

\section{Evoluçáo recente da Estrutura do Mercado de Trabalho e da Participaçáo Setorial do PIB da RMB}

A análise da evolução histórica dos dados disponíveis da distribuição setorial do PIB para a Cidade de Belém e sua regiáo Metropolitana, revela que, desde o ano de 1980, algo em torno de $88 \%$ da produção da cidade já se concentrava no setor terciário (Rodrigues, 1996, p. 110). O que comprova a importância deste setor na conformação do mercado de trabalho da RMB desde a década de 1980, início do processo de metropolização. Pode-se observar no Gráfico 1, que o setor serviços foi o que mais cresceu (quase duplicou na primeira década de 2000) mantendo uma trajetória de crescimento que reforça o argumento de metropolização durante todo o período.

GRÁFICO I | Comportamento do mercado de trabalho formal na RMB, 1998-2011

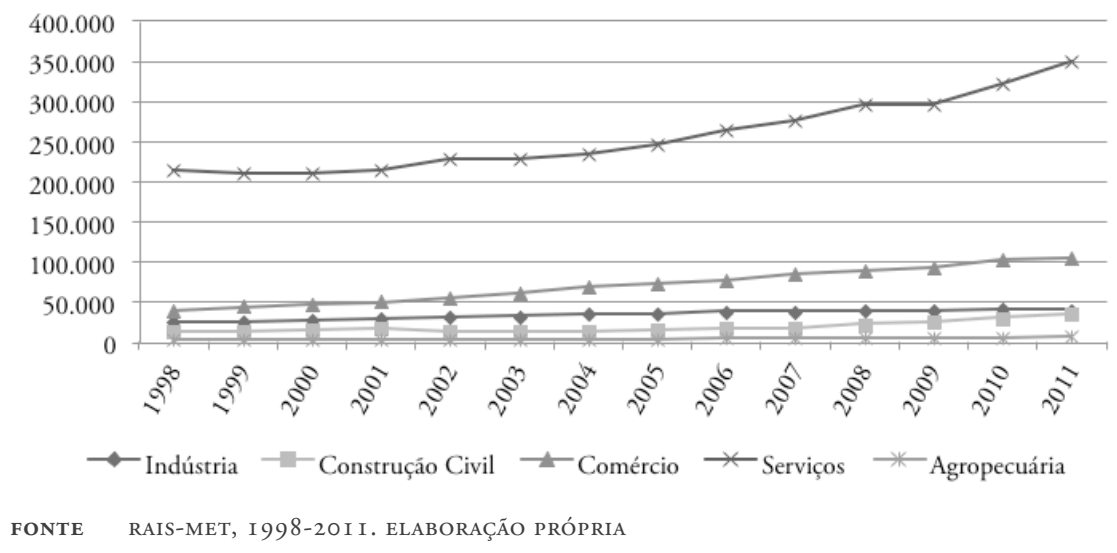

Para compreender porque o setor de serviços tem tido um destaque importante neste processo de crescimento, é fundamental voltar a atenção também para o papel da administração pública, pois, dos 350.129 trabalhadores empregados no setor de serviços em 2011, 176.114 correspondiam a servidores ou funcionários públicos, o que equivale a 50,3\% dos trabalhadores formais no setor de serviços. A expansão do emprego público, não exclusivo na RMB, pode ser um sintoma da ampliação dos serviços públicos -em especial, na cidade de Belém que é a capital do Estado-. Somam-se a isso o papel de centralidade na prestação de serviços públicos devido à necessidade de ampliação das demandas sociais frente ao desenvolvimento

5 Para mais detalhes sobre a discussão a respeito de urbanização desconcentrada ou difusa ver Domingues, 199:44-47. Disponível em http://www.apgeo.pt/files/docs/Inforgeo/INFORGEO_14_ p043a064.pdf. Acesso em: 25/11/2014. 
econômico e à crescente complexidade das atividades econômicas (proteção ao meio ambiente, regulação da concorrência, etc.) que tem exigido cada vez mais um papel da RMB como centro difusor e organizador das açóes do Estado em toda a região.

Esta tendência de crescimento dos empregos formais na RMB é acompanhada pela evolução da remuneração média mensal dos trabalhadores empregados no setor de serviço, o que se explica pelo nível de instrução requerida ser cada vez mais elevada (ver Gráfico 2).

\section{GRÁFICO 2 | Evolução da remuneração média mensal real na RMB, 2001-2011}

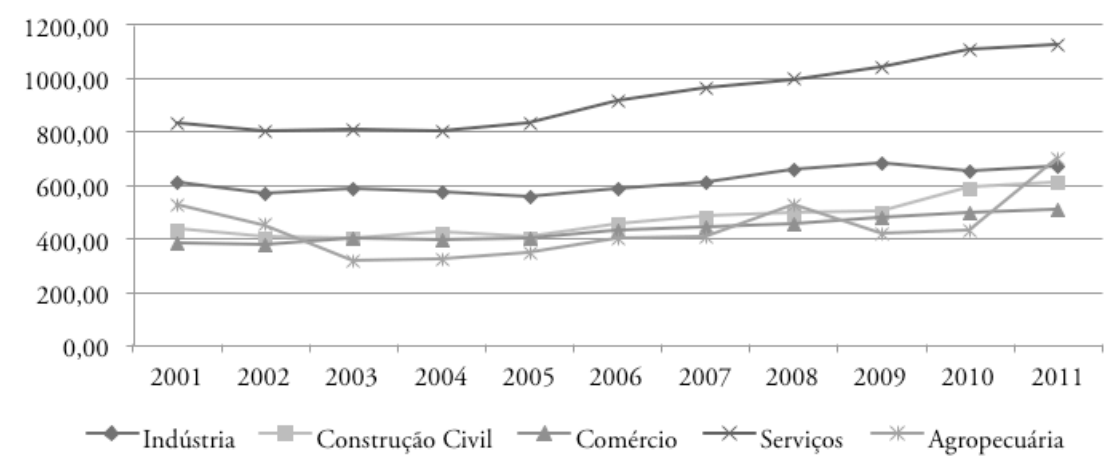

FONTE RAIS-MET, 2OOI-2OI I. ELABORAÇẤO PRÓPRIA

O Gráfico 3, por sua vez, demonstra que foi o setor privado (celetista) ${ }^{6}$ que teve o maior crescimento no período analisado, seguidos pelo setor público (estatutário). Esses resultados só reforçam a ideia exposta acima, ou seja, o setor de serviços está à frente do crescimento dos empregos formais (tanto público como privado) na RMB.

GRÁfICO 3 | Comportamento do mercado de trabalho formal na RMB segundo o tipo de vínculo, 2001-2011

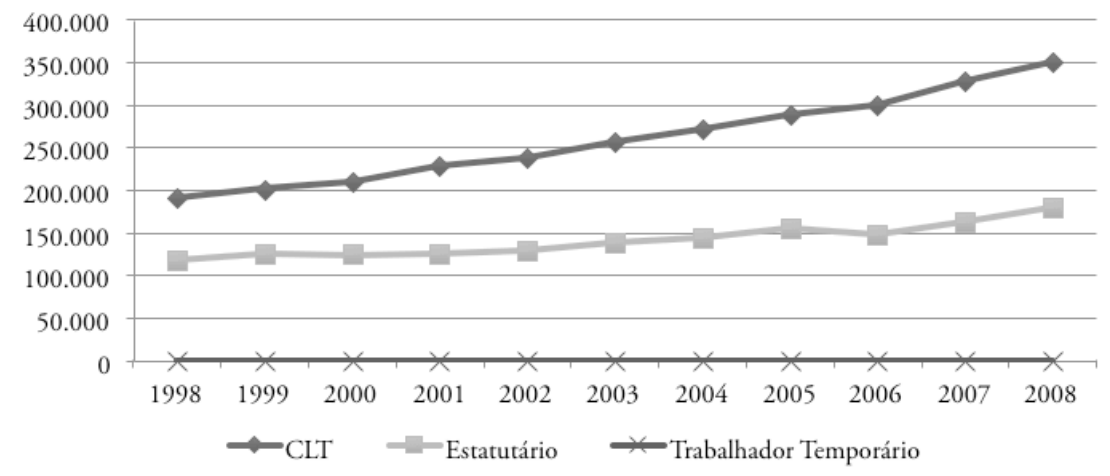

FONTE RAIS-MET, 2OOI-20I I. ELABORAÇĀO PRÓPRIA

6 No Brasil, o Regime de emprego vinculado à Consolidação das Leis Trabalhistas (CLT), em sua grande parte representa os empregos gerados por meio de contratos com empresas, o que reforça a sua utilização neste trabalho como proxy do nível de emprego do setor privado na economia. 
O Gráfico 4 mostra, por sua vez, o movimento de queda na participação relativa da atividade produtiva da RMB em relação ao Estado do Pará. De acordo com os dados do IBGE, em 1999, a RMB tinha uma participação de $42 \%$ na geração do PIB estadual, caindo, em 2010, para 32\%, uma queda de $10 \%$. Este movimento descendente é, claramente, um efeito do crescimento do PIв nos demais municípios paraenses a taxas mais elevadas que o grupo de municípios da região metropolitana (Instituto de Desenvolvimento Econômico, Social e Ambiental do Pará [IDEsP], 2012). O que vem a corroborar a hipótese de que estaria ocorrendo um processo de desconcentraçáo produtiva no sentido da RMB para municípios do interior do Estado do Pará.

\section{GráfICo 4 | Participação do PIB da RMB no PIB do Pará, 1999-2010}

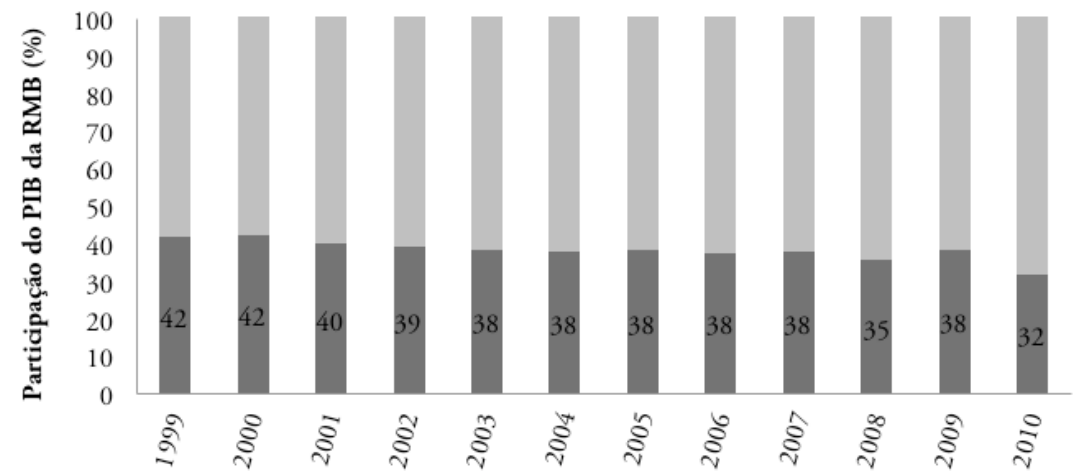

FONTE IBGE, SEPOF E SUFRAMA. ELABORAÇÃO PRÓPRIA

Dando continuidade à análise do PIB nominal, os dados do Gráfico 5 mostram ainda que o setor de serviços é também o maior responsável pela formação do PIB da região metropolitana de Belém. Diferentemente de outros espaços metropolitanos brasileiros, o espaço metropolitano de Belém não tem a indústria como elemento dinâmico de seu processo de metropolização ${ }^{7}$.

No entanto existem fatores estruturais mais profundos ligados ao papel da RмB no processo de expansão mais recente das atividades econômicas do interior do estado -que fortalecem seu papel histórico como centro urbano regional responsável, entre outras coisas, pelo fornecimento mais recente de uma ampla gama de serviços oferecidos em conexão com uma rede global de cidades- que explicam o crescimento do setor de serviços na RMB na década dos anos 2000.

7 Dados da RAIS desde 1985 demonstram que o setor secundário apresenta diversificação limitada de atividades, além de baixa modernização tecnológica e pouco dinamismo (<http://bi.mte.gov. br/bgcaged/rais.php>; Trindade Jr., 1998). Durante o período analisado o setor de alimentaçáo e bebidas manteve-se em média representando algo em torno de dois terços dos empregos na indústria na Rмв. 


\section{GRÁfico 5 | Comportamento do PIB Setorial na RMB, 1999-2010 Milhóes de R\$}

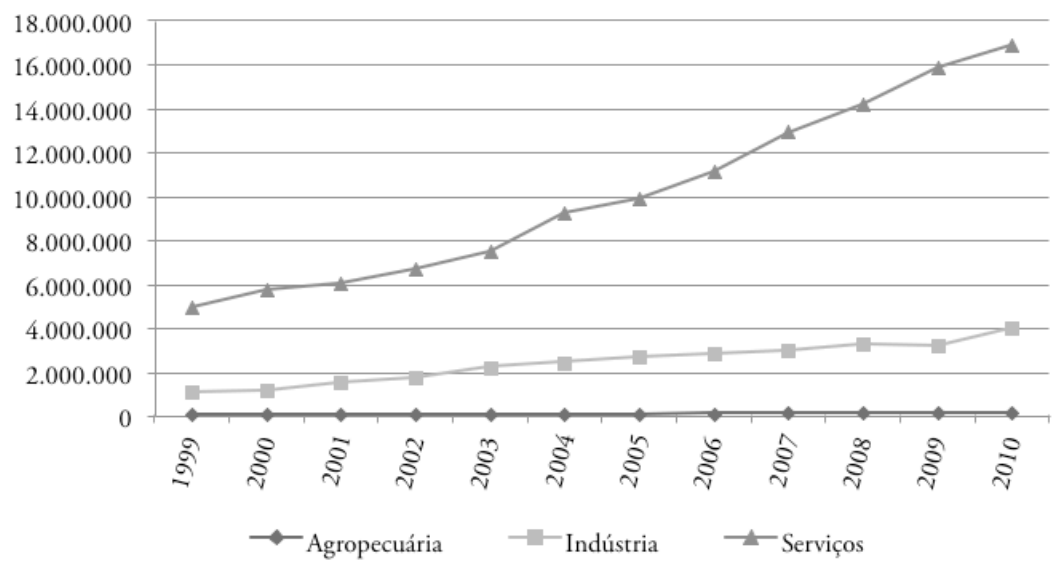

FONTE IBGE, SEPOF E SUFRAMA. ELABORAÇÃO PRÓPRIA

Esse componente do setor de comércio e serviços ligado ao mesmo tempo ao mercado nacional de produtos industriais representa, sem dúvida alguma, uma das grandes novidades e importante componente dinamizador mais recente do setor de serviços na Rмв. A comercialização de peças e serviços diretamente ligados ao setor de venda de automóveis, por exemplo, tem-se destacado como um dos principais elementos dinamizadores da economia local na última década. Neste sentido, novamente, em 2010, o setor de serviços na RMB aparece à frente dos demais na formação do PIB, contando com a participação da atividade de comércio, na qual se destacou o segmento de venda no atacado de combustíveis, loja de departamento, veículos e produtos alimentícios, como também as subatividades da administração pública e intermediaçóes financeiras (IDESP, 2012).

Avaliando mais a fundo a questão em torno da atividade econômica no setor terciário, de acordo com os dados da pesquisa Cadastro Geral de Empresas

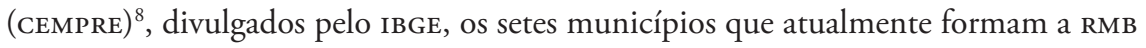
concentravam, em 1999, 22.748 estabelecimentos, dos quais 90,9\% representavam o setor de Serviços e Comércio (ver Gráfico 6a). Em 2010, o total de empresas do setor terciário teve um acréscimo de 3.718 estabelecimentos, perfazendo, então, 92,6\% das unidades empresariais na RMB neste ano (ver Gráfico 6b).

A base de dados do CEMPRE permite visualizar, também, que as atividades relacionadas à compra e venda de mercadorias no setor terciário, incluindo a manutenção e reparação de veículos automotores, têm um grande peso sobre a dinâmica econômica metropolitana de Belém.

8 Pesquisa divulgada anualmente pelo IBGE que fornece informaçôes sobre o número de unidades locais, pessoal ocupado, salários e outras remuneraçōes, de empresas formalmente constituídas, registradas no Cadastro Nacional de Pessoa Jurídica-CNPJ e ativas no ano do levantamento. 
Quando o conjunto de empresas que constituem apenas o setor de serviços na RMB é desagregado, compóe-se o seguinte quadro: dos quinze segmentos que formam o setor de serviços, totalizando 12.501 unidades locais de empresas; 20,2\% são de outras atividades de serviços ${ }^{9}, 18,2 \%$ atividades administrativas e serviços complementares, $11,1 \%$ atividades profissionais, científicas e técnicas, $10,5 \%$ alojamento e alimentação, 9,4\% transporte, armazenagem e correio e $9,0 \%$ saúde humana e serviços sociais. É digno de nota que o município de Belém é que puxa estas atividades, pois, sendo a capital e a cidade melhor infraestruturada do Estado, acaba por apresentar expressiva oferta de serviços ligados ao setor público, o que ajuda a colocá-lo na dianteira na prestação de serviços na RMB.

\section{GRÁFICo 6A | Distribuição das empresas GRÁFICo 6B | Distribuição das empresas na RMB, segundo o setor, 1999 na RMB, segundo o setor, 2010}

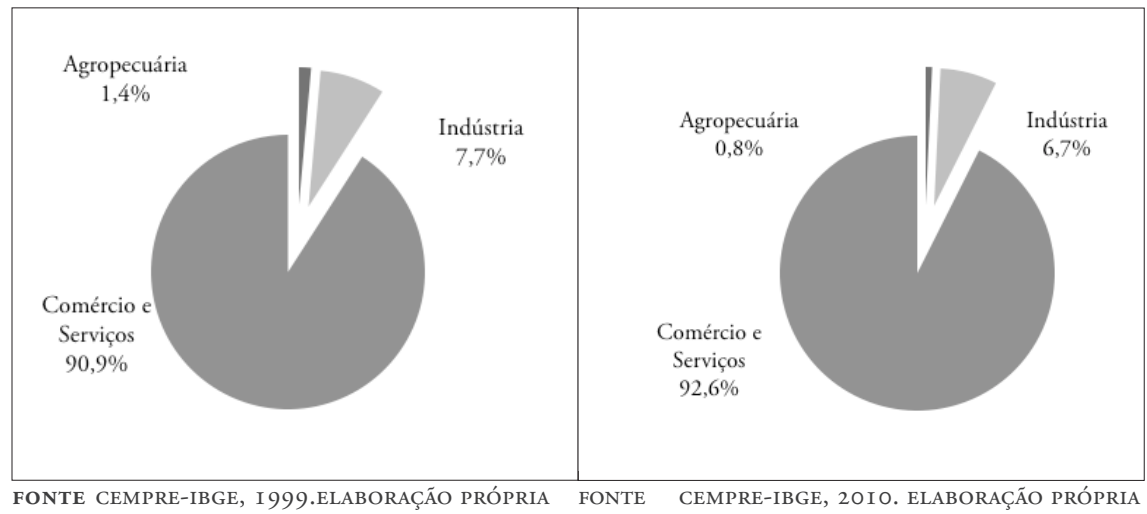

Um exercício de desagregação do o setor de Comércio na RMB, gera a seguinte configuração: a) a venda por atacado e a varejo de veículos automotores e motocicletas novas e usadas e de peças e acessórios respondia apenas por 1,1\% do total das 13.582 unidades locais de empresas do setor de Comércio nesta região; b)a revenda de mercadorias novas ou usadas, sem transformação, a varejistas, a usuários industriais, agrícolas, comerciais, institucionais e profissionais ou a outros atacadistas (comércio atacadista em geral), abrangia $15,8 \%$ do total; enquanto que c) a revenda de mercadorias novas e usadas, principalmente ao público em geral, para consumo, uso pessoal ou doméstico (comércio varejista em geral), correspondia a 74,6\% do total.

Dentre as 10.128 unidades locais de empresas da área do varejo na região, em 2011, 68,5\% estavam concentradas na cidade de Belém. Tais dados evidenciam que é o comércio varejista de Belém que dá conformação à dinâmica econômica da área metropolitana. O Gráfico 7 nos mostra que, embora tenha ocorrido uma perda na participação das empresas comerciais no total de empresas da RMB entre 2006 e 2011, o comércio continua a agregar mais de 50\% das unidades empresariais na regiáo.

9 Refere-se a atividades como manutenção de equipamentos de informática, comunicação e objetos domésticos, atividades de organizaçôes associativas e outras atividades de serviços pessoais. 


\section{GRÁfICo 7 | Participação das Empresas de Comércio na RMB, 2006-2011}

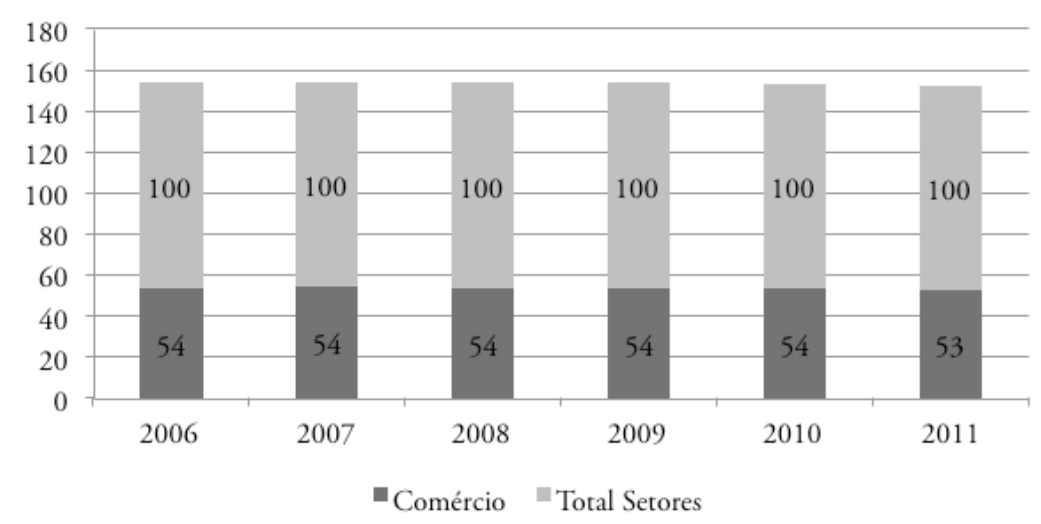

FONTE CEMPRE-IBGE, 2006-20I I. ELABORAÇÃO PRÓPRIA

Como um todo, neste ponto, vale ressaltar o papel da região metropolitana como "centro relacional", como destaca Santos (1993). Ou seja, como elo ou centro fundamental que articula (busca, manipula e fomenta) diversos níveis de informação e a utiliza em favor da economia, através da prestação de serviços de fundamental importância para o funcionamento da dinâmica econômica (agropecuária e industrial) de vários municípios do interior. Dai um dos principais pontos e motivos da manutenção do papel de centralidade da RMB, apesar da diminuição de sua participação relativa no PIB estadual.

\section{Consideraçóes finais}

A antiga rede de cidades, chamada de dendritica, foi instrumental para a racionalidade comercial e militar, originariamente voltada para a conquista e defesa de um determinado território e para a navegação dos rios. Esta deu lugar a uma rede urbana em que cidades como Marabá, Santarém e Castanhal passaram a cumprir o papel de cidades médias articuladas não mais pelos rios, mas sim por um eixo de integração rodoviária. Ainda que essa expansão e o aumento da complexidade da rede urbana na Amazônia Oriental não sejam capturados pelas métricas nacionais em todos as suas nuances (IBGE, 2008; Simóes et al., 2013), já há uma clara manifestação na regiấo da lógica urbano-industrial prevalecente no país, deslanchada com a política de integração nacional.

O crescimento de atividades produtivas e do processo de integração territorial do Pará ao Brasil teria desempenhado um papel significativo no processo de formação dessa nova rede de cidades na Amazônia (Corrêa, 1987). Este fenômeno estaria ligado tanto ao processo de concentração e especialização de vários ramos de atividades comerciais e de serviços nas capitais dos Estados amazônicos, quanto ao processo de desconcentração das atividades industriais e agropecuárias.

Ribeiro (2001), seguindo Corrêa (1987), argumenta que, com o processo de integração da Amazônia ao país a partir da década de 1960, inicia-se um aumento 
na complexidade funcional dos centros urbanos na regiáo, com uma crescente divisão do trabalho entre cidades que passam a compor redes de interaçóes espaciais geradoras de diferentes tipos de papéis, tais como: o de produção, distribuição e gestão de recursos e do excedente econômico gerado na economia regional. Neste contexto, grandes regióes metropolitanas, como Belém, começam a se destacar como centros regionais de importância agora ligadas a um papel menos dependente diretamente de atividades produtivas industriais e agrícolas. Assim, a rede de comércio e serviços é que passa a representar o centro e fonte renovada do vigor polarizador da região metropolitana de Belém.

$\mathrm{Na}$ Amazônia Oriental há dinamismo intenso e crescimento maior na área de influência da RMB do que na própria metrópole (Belém), devido ao direcionamento de investimentos e à implantaçáo de grandes empreendimentos em sub-regióes do Estado, a exemplo do projeto Carajás no sudeste do Pará, contudo isso não significou perda de importância do espaço metropolitano no que diz respeito aos processos dinamizadores da economia regional, e sim, uma redefinição dessa importância (Trindade Jr., 1998).

Belém tornou-se um centro onde, de acordo com Milton Santos (1993), buscase, manipula e fomenta informaçóes a serem utilizadas em favor da economia, da sociedade, da política e da cultura industriais, mas que ainda recebe grande parte da mão de obra móvel e eclética que circula no espaço regional. Como um todo, o que podemos perceber é que, apesar da RMB passar a perder parcela significativa de sua participação econômica em atividades produtivas na região, a mesma ainda mantém seu grau de centralidade, na medida em que fortalece seus elos na produçáo de serviços e como grande centro difusor de informaçóes que alimenta toda a dinâmica econômica em seu entorno. Nessa perspectiva, esse fenômeno da urbanizaçáo associada à lógica da integraçáo do espaço regional com os mercados nacional e internacional convive com outra modalidade de urbanização bem menos reconhecida, mas não menos importante, comumente associado à falta de oportunidades e baixa capacidade de modernização do espaço da várzea e que contribui para a formação dos bolsôes de pobreza e intensidade das ocupaçóes informais nas áreas alagáveis da capital, mas que mostra o reverso do amálgama composto pela associação das práticas tradicionais de ocupação do território e dinâmicas mercantis difundidas através da rede dendrítica secular à ação do capital globalizado, cuja população deseja integrar-se à sociedade de consumo e à vida metropolitana, mas ainda não descobriu como atravessar as pontes etéreas que articulam esses dois mundos.

\section{Referências bibliográficas}

Araújo, T. (1999). Brasil nos anos 90: opçōes estratégias e dinâmica regional. Revista Brasileira de Estudos Urbanos e Regionais, (2), 9-24.

Ares, S. \& Mikkelsen, C. (2009/2010). Nuevas dinámicas residenciales en los asentamientos rurales del litoral sudeste pampeano. Breves Contribuciones del Instituto de Estudios Geográficos, (21), 104-134. Disponível em http://dialnet.unirioja.es/servlet/ articulo? codigo $=3947079$ 
Belussi, F. (1996). Local systems, industrial districts and institutional networks: towards a new evolutionary paradigm of industrial economics. European Planning Studies, 4(1), 5-26. doi: $10.1080 / 09654319608720326$

Becker, B. (2013). A Urbe Amazônida. Rio de Janeiro: Garamond.

Becker, B. (1982). Geopolítica da Amazônia: a nova fronteira de recursos. Rio de Janeiro: Zahar.

Becker, B. (1985). A fronteira em fins do século xx-Oito proposiçôes para um debate sobre a Amazônia. Espaço e Debate, 4(13), 59-73.

Becker, B. (1990). Significados da Defesa da Amazônia: Projeto geopolitico ou fronteira tecno(eco)lógica para o século Xxi? Antropologia e Indigenismo (Rio de Janeiro), 1.

Brasil. (2008). Ministério do Planejamento Orçamento e Gestão, Secretaria de Planejamento e Investimentos Estratégicos. Estudo da Dimensão Territorial para o Planejamento. Brasília.

Camargo, J. (1973). Urbanismo Rural. Brasília: Instituto Nacional de Colonização e Reforma Agrária (INCRA).

Castells, M. (1983). A Questão Urbana. São Paulo: Paz e Terra.

Coelho, G. (2005). Anteato da belle époque: imagens e imaginação de Paris na Amazônia de 1850. Revista de Cultura do Pará, 16(2), 199-215.

Corrêa, R. (1987). A periodização da rede urbana da Amazônia. Revista Brasileira de Geografia (Rio de Janeiro), 4(3), 39-68.

Costa, F. (2012a). Formação agropecuária na Amazônia, o desafio do desenvolvimento sustentável. Belém: Núcleo de Altos Estudos Amazônicos (NAEA).

Costa, F. (2012b). Formação Rural Extrativista na Amazônia: Os desafios do desenvolvimento Capitalista (1720-1970). Belém: Núcleo de Altos Estudos Amazônicos (NAEA).

Domingues, E., Carvalho, T. \& Magalhães, A. (2013). Cenário de Referência e Impactos de Investimentos Públicos e Privados no estado do Pará, 2006-2020. Anexo D. In M. Monteiro \& A. Cardoso, Relatório UrbisAmazônia ano 2. São José dos Campos: Instituto Nacional de Pesquisas Espaciais (INPE). Disponível em http://www.dpi.inpe. br/urbisAmazonia/doku.php?id=urbis:producao, acesso jan 2014.

Domingues, A. (1999). Formas e escalas da urbanização difusa-Interpretação e Intervenção no NO de Portugal. Inforgeo, 14, 43-64. Disponível em http://www.apgeo.pt/files/docs/ Inforgeo/inforgeo_14_p043a064.pdf

Emmi, M. (2010). A Amazônia como destino das migrações internacionais do final do século XIX ao início do séculoXX: o caso dos portugueses. XVII Encontro Nacional de Estudos Populacionais 2010: População e Desenvolvimento-decifrando Conexöes, Caxambu, MG, Brasil.

Grandin, G. (2009). Fordlândia. Ascensão e queda da cidade esquecida de Henry Ford na Amazônia. São Paulo: Rocco.

Instituto Brasileiro de Geografia e Estatística (IBGE). (2008). Estudo de Regionalização de Cidades (REGIC). Rio de Janeiro: IBgE.

Instituto de Desenvolvimento Econômico, Social e Ambiental do Pará (IDESP). (2012). Produto Interno Bruto Estadual 2010. Belém, v. 1, n.1, pp. 1-108, jan.-dez. Disponível em http://www.idesp.pa.gov.br>. Acesso em: 15 ago. 2013. 
Instituto de Pesquisa Econômica Aplicada (IPEA)/Instituto Brasileiro de Geografia e Estatística (IBGE)/Universidade Estadual de Campinas (Unicamp). (2001). Caracterização $e$ tendências da rede urbana do Brasil: estudos básicos para caracterizaçâa da rede urbana. Brasília: IPEA.

Machado, L. (1992). Fronteira agrícola na Amazônia Brasileira. Revista Brasileira de Geografia, 54(2), 27-55.

Machado, L. (1998). Limites, Fronteira e Redes. In T. Strohaecker \& A. Damiani (Orgs.), Fronteiras e Espaço Global (pp. 41-49). Porto Alegre: Associaçáa dos Geógrafos Brasileiros (AGB).

Lencioni, S. (1994). Reestruturação urbano-industrial no Estado de Sáo Paulo: a regiáo da metrópole desconcentrada. Em M. Santos, M.A. de Souza, M.L. Silveira (Orgs.), Território: Globalização e fragmentação (pp. 198-210). São Paulo: Hucitec.

Martins, J. (1975). Capitalismo e tradicionalismo. São Paulo: Pioneira.

Marx, M. (1991). Cidade no Brasil Terra de Quem? São Paulo: Nobel/Editora da Universidade de Sáo Paulo (Edusp).

Ministério do Interior/Serviço Federal de Habitação e Urbanismo. (1972). Planejamento Urbano e Local e o Desenvolvimento das Faixas Pioneiras. Brasília: Minter/Serfhau.

Mitschein, T., Miranda, H. \& Paraense, M. (1989). A urbanização selvagem e a proletarização passiva na Amazônia-o caso de Belém. Belém: Editora cejup.

Monte-Mor, R. (2004). Modernities in the Jungle: Extended Urbanization in the Brazilian Amazonia. Unpublished Ph.D. Thesis. Los Angeles: University of California.

Penteado, A. (1968). Estudo de geografia urbana de Belém. Belém: Universidade Federal do Pará (UFPA).

Pereira, J. (2006). A Urbanização da Amazônia e o papel das Cidades Médias na Rede Urbana Regional. In A. Cardoso (Org.), O Rural e o Urbano na Amazônia: diferentes olhares em perspectiva. Belém: Universidade Federal do Pará (UFPA).

Pinheiro, A.; Pena, H.; Amaral, M. \& Herreros, M. (2011). Dinâmica urbana do Estado do Pará (2000-2008). In R. Pereira \& B. Furtado (Orgs.), Dinâmica Urbano-Regional: Rede Urbana e suas Interfaces (pp. 145-182). Brasília: Instituto de Pesquisa Econômica Aplicada (IPEA).

Programa das Naçôes Unidas para o Desenvolvimento (PNUD-Brasil), Instituto de Pesquisa Econômica Aplicada (IPEA), Fundação João Pinheiro (FJP). (2013). Atlas do Desenvolvimento Humano no Brasil 2013. Disponível em http://atlasbrasil.org. br/2013/download/

Ribeiro, M. (2001). A rede urbana amazônica-Da rede dendrítica à configuração de uma rede complexa. In Cidades: Urbanização e perspectivas geográficas (pp. 369-389). São Paulo: Gasper/Editora da Universidade de São Paulo (Edusp).

Rodrigues, E. (1996). Aventura urbana: urbanização, trabalho e Meio-ambiente em Belém. Belém: Editora NAEA.

Santos, M. (1979). O Espaço Dividido: os dois circuitos da economia urbana dos países subdesenvolvidos. São Paulo: Francisco Alves Editora S. A.

Santos, M. (1993). A urbanização brasileira. São Paulo: Hucitec.

Santos, M. \& Silveira, M. (2001). O Brasil: território e sociedade no início do século xxi. São Paulo: Record.

Santos, R. (1980). História econômica da Amazônia (1800-1920). São Paulo: T.A. Queiroz. 
Sarges, M. (2002). Belém: riquezas produzindo a Belle-Époque (1870-1912). Belém: Paka-Tatu. Sawyer, D. (1979). Peasants and capitalism on the Amazon Frontier. Ph.D. Dissertation. Department of Sociology, Harvard University, Cambridge, MA.

Simões, R., Garcia, R., Lima, A. \& Amaral, P. (2013). Caracterização das redes de cidades no Estado do Pará e na Amazônia Legal Expandida e identificação de novas centralidades Anexo E. In M. Monteiro \& A. Cardoso, Relatório UrbisAmazônia ano 2. São José dos Campos: Instituto Nacional de Pesquisas Espaciais (INPE). Disponível em http://www. dpi.inpe.br/urbisAmazonia/doku.php?id=urbis:producao

Trindade Jr. S. (1998). A cidade dispersa: os novos espaços de assentamentos em Belém e a reestruturação metropolitana. Tese de Doutorado. Programa de Pós-graduação em Geografia, Universidade de São Paulo, São Paulo, sp, Brasil.

Trindade Jr. S. \& Pereira, J. (2007). Reestruturação da Rede Urbana e Importância das Cidades Médias na Amazônia Oriental. In M. Spósito (Org.), Cidades Médias: Espaços em Transição (Vol. 1, pp. 313-342). São Paulo: Expressão Popular.

Silva, M. (1949). Geografia dos transportes no Brasil. Rio de Janeiro: Instituto Brasileiro de Geografia e Estatística (IBGE).

Ventura Neto, R. (2012). Circuito imobiliário e a cidade: coalizóes urbanas e dinâmicas de acumulação do capital no espaço intraurbano de Belém. Dissertação de Mestrado, Programa de Pós-graduação em Arquitetura e Urbanismo, Universidade Federal do Pará, Belém, PA, Brasil.

Vicentini, Y. (2004). Cidade e história na Amazônia. Curitiba: Editora da Universidade Federal do Paraná. 
